\title{
PENERAPAN ACTIVITY BASED COSTING SYSTEM DALAM MENENTUKAN HARGA POKOK KAMAR HOTEL (STUDI PADA HOTEL GREEN EDEN MANADO)
}

\author{
Shelby Estereniy Siby ${ }^{1}$, Ventje Ilat ${ }^{2}$, Meily Y.B Kalalo ${ }^{3}$ \\ ${ }^{1,2,3}$ Jurusan Akuntansi, Fakultas Ekonomi dan Bisnis, Universitas Sam Ratulangi, Jl. Kampus Bahu, Manado, \\ 95115, Indonesia \\ E-mail : shelbyestereniy16@gmail.com
}

\begin{abstract}
The Activity of Based Costing (ABC) Method is a simple calculation to determine the cost of price / services to explain that the activity were the reason one to make rise the cost of the products, and products that consume activity.The hotel can use Activity Based Costing $(A B C)$ System Method to determine hotel room rate because when they use the Activity economic method in detail, the quality of decision can be improve to be better and making more accurate. The purpose of this research is "to obtain the accurate information about Activity Based Costing" in counting the cost calculation rooms Hotel Green Eden Manado since from June, July, and August 2017. The method of analysis that I used is "Descriptive Analysis Method", by conducting to interview to the hotel manager and doing the data collection regarding the costs and amounts of fees. Based on the analysis, there are find that Activity Based Costing System for the month of June. Superior room type, Deluxe room and Suite resulted that the cost of price rooms were lower to compared with the cost by hotel management. For July the calculation of the cost Superior room type was higher than the cost of calculated by the management Hotel. And for the type of Deluxe rooms and Suite rooms were lower to compared with the cost by the Hotel. And for the month of August the calculation for Superior, Suite, and Deluxe rooms resulted that the cost were higher than the cost calculation used by The Hotel Management.
\end{abstract}

Keywords : Activity Based Costing, The cost of rooms.

\section{PENDAHULUAN}

Perkembangan usaha di Indonesia dalam dekade terakhir ini sangat berkembang. Akibat dari berkembangnya usaha tersebut adalah naiknya persaingan bisnis antar perusahaan. Setiap perusahaan harus memiliki strategi dan inovasi supaya tidak tenggelam dalam arus bisnis. Semakin menjamurnya perusahaan jasa terutama yang bergerak di bidang pariwisata dan perhotelan, menyebabkan semakin ketatnya persaingan antar hotel. Biaya hotel merupakan salah satu yang menarik hati konsumen.

Oleh karena itu diperlukan strategi-strategi perusahaan yang bisa menangkan perusahaan dalam persaingan. Menurut Panakenan (2014) strategi yang digunakan untuk bisa memenangkan dalam persaingan adalah menekanan harga jual produk, karena harga jual semakin rendah, maka tingkat penjualan produkpun akan menjadi tinggi.

Harga pokok adalah nilai dari sesuatu yang dikorbankan dan diukur dalam satuan uang untuk memperoleh aset yang diimbangi dengan aset berkurang atau utang/modal bertambah (Nafarin, 2013)

$A B C$ adalah metode menghitung harga pokok produk atau jasa dasarnya yaitu aktivitaslah yang menyebabkan biaya itu timbul, dan produklah pengonsumsi aktivitas. Dalam $A B C$, biaya-biaya tidak langsung ditentukan melalui aktivitas yang ada, tapi biaya 
untuk masing-masing aktivitas tesebut kemudian dibebankan produk atas dasar konsumsi yang masing-masing produk pada aktivitas.

Sistem $A B C$ dapat menyediakan informasi perhitungan biaya yang lebih baik dan dapat membantu manajemen mengelola perusahaan secara efisien serta memperoleh pemahaman yang lebih baik atas keunggulan, kekuatan, dan kelemahan perusahaan. Melalui dengan metode ini dapat menyajikan informasi harga pokok produk atau jasa secara cermat dan akurat bagi kepentingan manajemen.

Manado merupakan kota yang pariwisatanya sedang meningkat sangat drastis. Manado banyak dikunjungi oleh wisatawan mancanegara untuk berwisata bahkan adapula yang datang dengan tujuan bisnis. Peningkatan industri wisata yang sangat tinggi menyebabkan kebutuhan akan tempat penginapan semakin tinggi, sehingga para wisatawan memerlukan informasi tarif kamar hotel yang tepat dan akurat. Salah satu penyedia jasa di bidang perhotelan adalah Hotel Green Eden Manado. Hotel Green Eden Manado menyediakan empat tipe kamar, yaitu kamar Superior twin, kamar Deluxe double dengan pemandangan laut, kamar Superior double, dan kamar Deluxe double dengan pemandangan kota. Hotel Green Eden Manado belum menggunakan metode Activity Based Costing System tetapi masih menggunakan metode tradisional yaitu menghitung semua biaya yang dikeluarkan dan dibagi dengan tiap tipe kamar yang dihasilkan dan menambahkan mark-up sesuai ketentuan pihak manajemen hotel, serta diikuti setiap event yang ada di Manado. Tidak tepat menggunakan metode tradisional dalam penentuan harga yang harus dibayar oleh pelanggan. Manajemen hotel dapat mencoba metode Activity Based Costing System dalam penentuan harga kamar hotel Green Eden karena penggunaan aktivitas yang detail akan memberi manfaat dalam meningkatkan kualitas dalam pengambilan keputusan yang lebih akurat, dan peneliti ingin melihat perbandingan harga pokok dari kedua metode tersebut.

\section{TINJAUAN PUSTAKA \\ 2.1 Biaya \\ 2.1.1 Pengertian Biaya}

Biaya berpengertian sebagai sebuah pengorbanan untuk menghasilkan, dinyatakan dengan satuan uang berdasarkan harga pasar yang berlaku, Menurut Siregar dkk (2013). "Biaya merupakan pengorbanan sumber ekonomi untuk memperoleh barang atau jasa yang memberi manfaat untuk saat ini atau masa yang akan datang".

\subsubsection{Klasifikasi Biaya}

Pengelompokan biaya atas seluruh elemen biaya yang ada ke dalam golongangolongan tertentu yang lebih ringkas dan dapat memberikan informasi yang lebih ringkas dan penting disebut Klasifikasi Biaya. Yang umum digunakan dalam klasifikasi biaya berhubungan dengan Produk, Volume produksi, Departemen dan pusat biaya, Periode akuntansi, Pengambilan keputusan

\subsection{Harga Pokok Produksi}

\subsubsection{Pengertian Harga Pokok Produksi}

Harga pokok produksi merupakan biaya-biaya yang harus dikeluarkan untuk memproduksi suatu barang atau jasa yang dinyatakan melalui uang. Jumlah dari seluruh biaya yang diperlukan untuk memperoleh dan mempersiapkan semuanya barang untuk dijual disebut dengan harga pokok penjualan (cost of good sold).

\subsubsection{Fungsi Harga Pokok Produksi}

Harga pokok produksi memiliki beberapa fungsi, yaitu:

1. Harga pokok sebagai penetapan harga jual

2. Harga pokok sebagai dasar penetapan laba

3. Harga pokok sebagai dasar penilaian efisiensi

4. Harga pokok sebagai dasar pengambilan berbagai keputusan manajemen 


\subsubsection{Metode Penentuan Harga Pokok Produksi}

Dalam menghitung harga pokok produksi biasanya memakai metode tradisional, komponen-komponen harga pokok produk atau jasa terdiri dari biaya bahan baku langsung, biaya tenaga kerja langsung dan biaya overhead baik yang bersifat tetap atau variabel.

\subsection{Metode Tradisional}

akuntansi tradisional merupakan semua biaya dibebankan ke produk bahkan biaya produksi yang tidak disebabkan oleh produk.

Pada tahap pertama, seluruh biaya tidak langsung dibebankan kepada kelompok biaya (cost pools) atau pusat biaya yang merupakan objek dasar biaya selanjutnya biaya dari cost pools akan dibebankan kepada produk atau jasa yang dihasilkan sebagai objek biaya akhir dengan menggunakan dasar alokasi.

\subsection{Metode Activity Based Costing}

\subsubsection{Pengertian Activity Based Costing}

Biaya itu berdasarkan aktivitas yaitu sebagai pendekatan yang digunakan untuk penentuan biaya produk dengan cara yaitu membebankan biaya ke produk atau jasa dengan dasar atas konsumsi sumber daya oleh aktivitas tersebut. (Rudianto, 2013)

\subsubsection{Klasifikasi Aktivitas}

Ada 4 tingkatan aktivitas pada metode Activity Based Costing yaitu: Tingkat Unit (Unit Level), Tingkat Batch (Batch Level), Tingkat Produk (Product Level), dan Tingkat Fasilitas (Facility Level)

\subsubsection{Langkah-langkah Peritungan dengan Metode Activity Based Costing}

Tahap-tahap penerapan perhitungan biaya dengan metode $A B C$ adalah:

1. Prosedur Tahap Pertama (First-stage Allocation)

2. Prosedur Tahap Kedua (Second-stage Allocation)

\subsection{Pembebanan Biaya Overhead pada Activity Based Costing}

Pada Activity Based Costing meskipun pembebanan biaya-biaya overhead pabrik dan produk juga menggunakan dua tahap seperti pada akuntansi biaya tradisional, tetapi pusat biaya yang dipakai untuk pengumpulan biaya-biaya pada tahap pertama dan dasar pembebanan dari pusat biaya kepada produk pada tahap kedua sangat berbeda dengan akuntansi biaya tradisional.

\subsection{Cost Pool}

Cost pool merupakan pengelompokan biaya yang disebabkan oleh aktivitas yang sama dengan satu dasar pembebanan (cost driver). Cost pool tersebut berisi aktivitas yang biayanya memiliki hubungan yang kuat antara cost driver dengan biaya aktivitas. Setiap cost pool menampung biaya-biaya dari transaksi-transaksi homogen.

\subsection{Cost Driver}

Cost Driver adalah pemicu biaya seperti variabel, seperti tingkat aktivitas atau volume yang menjadi dasar timbulnya biaya dalam rentang waktu tertentu. Artinya ada hubungan sebab dan akibat antara perubahan tingkat aktivitas atau volume dengan perubahan tingkat biaya total.

\subsection{Sistem Activity Based Costing pada Perusahaan Jasa}

Sistem Activity Based Costing pada awalnya diterapkan pada perusahaan manufaktur. Untuk pertama kalinya perusahaan jasa dan perusahaan dagang serta organisasi sektor publik dan organisasi nirlaba dapat memanfaatkan sistem informasi biaya yang sangat bermanfaat untuk mengurangi biaya dan penentuan secara akurat harga pokok produk/jasa.

Namun, ada beberapa perbedaan dasar antara perusahaan jasa dan manufaktur. Kegiatan dalam perusahaan manufaktur cenderung menjadi jenis yang sama dan dilaksanakan dengan cara yang serupa. Hal ini berbeda untuk perusahaan jasa. 
Untuk menjawab permasalahan di atas, Activity Based Costing benar-benar dapat digunakan pada perusahaan jasa, setidak-tidaknya pada beberapa perusahaan. Yang perlu diperhatikan dalam menerapakan Activity Based Costing pada perusahaan jasa adalah:

1. Identifying and Costing Activities

2. Special Challenger

3. Output Diversity

\subsection{Hotel}

Hotel merupakan usaha akomodasi atau perusahaan yang menyediakan pelayanan bagi masyarakat umum dengan fasilitas jasa penginapan, penyedia makanan dan minuman, jasa layanan kamar, serta jasa pencucian pakaian. Seluruh fasilitas tersebut diperuntukan bagi mereka mereka yang bermalam di hotel tersebut ataupun mereka yang hanya menggunakan fasilitas tertentu yang dimiliki hotel itu.

\section{METODE PENELITIAN}

\subsection{Jenis Penelitian}

Jenis penelitian yang digunakan adalah penelitian kualitatif dimana peneliti secara langsung mendatangi objek penelitian yaitu Hotel Green Eden Manado untuk memperoleh data-data dan informasi yang berhubungan dengan permasalahan yang dihadapi. Data merupakan keterangan-keterangan yang diperoleh dari penelitian atau melalui referensireferensi untuk menganalisis perbedaan antara penentuan harga pokok kamar hotel menggunakan metode yang diterapkan pihak hotel selama ini dan dengan menggunakan Activity Based Costing System.

\subsection{Tempat dan Waktu Penelitian}

Lokasi penelitian merupakan suatu tempat atau wilayah dimana penelitian tersebut akan dilakukan.

1. Tempat Penelitian

Penelitian ini bertempat di Hotel Green Eden Manado, Jl. Ahmad Yani No.17 Sario, Manado, Sulawesi Utara

2. Waktu Penelitian

Penelitian dilaksanakan pada September - November 2017.

\subsection{Metode analisis}

Prosedur penelitian adalah langkah-langkah yang digunakan sebagai alat untuk mengumpulkan data dan menjawab pertanyaan-pertanyaan dalam penelitian. Berikut langkah-langkahnya:

1. Permohonan mengadakan penelitian pada Hotel Green Eden Manado.

2. Tahap pengumpulan data dilakukan dengan observasi langsung ke Hotel Green Eden Manado. Mewawancarai pihak Manajemen dan Akuntan hotel meminta data yang dibutuhkan untuk menunjang penelitian.

3. Menginterpretasikan data: mengaitkan data yang ada dengan kajian pustaka atau teori terkait. Dalam hal ini mengklasifikasi biaya dengan dasar aktivitas, identifikasi cost driver, dan penentuan tarif per unit.

4. Menarik Kesimpulan

\subsection{Metode Pengumpulan Data}

Data kualitatif merupakan data yang berbentuk kata, kalimat, gerak tubuh, ekspresi wajah, bagan, gambar dan foto. Data kualitatif yang didapat seperti gambaran umum hotel, prosedur hotel, dan pembagian tugas dalam hotel. Adapun data yang digunakan dalam penelitian ini adalah jenis data kualitatif deskriptif. 


\section{HASIL ANALISIS DAN PEMBAHASAN}

\subsection{Hasil analisis}

Harga pokok kamar menurut Hotel Green Eden Manado 3(tiga) jenis tipe kamar yang ada di Hotel Green Eden Manado yaitu Superior, Deluxe, dan Suite. Jumlah kamar yang terjual untuk setiap kamar yang ada di hotel Green Eden Manado pun berbeda-beda.

Tabel 4.1 Jumlah kamar yang tersedia untuk dijual

\begin{tabular}{|c|c|c|c|c|}
\hline Jenis Kamar & $\begin{array}{c}\text { Jumlah kamar } \\
\text { (1) }\end{array}$ & $\begin{array}{c}\text { Jumlah Kamar } \\
\text { (Juni 2017) } \\
\text { (1)x 30 hari }\end{array}$ & $\begin{array}{c}\text { Jumlah Kamar } \\
\text { (Juli 2017) } \\
(\mathbf{1}) \mathbf{x} 31 \text { hari }\end{array}$ & $\begin{array}{c}\text { Jumlah Kamar } \\
\text { (Agustus 2017) } \\
\text { (1)x 31 hari }\end{array}$ \\
\hline Superior & 13 & 390 & 403 & 403 \\
\hline Deluxe & 15 & 450 & 465 & 465 \\
\hline Suite & 8 & 240 & 248 & 248 \\
\hline Jumlah & 36 & 1.080 & 1.116 & 1.116 \\
\hline
\end{tabular}

Sumber : Data diolah 2017

Tabel 4.2 Jumlah hari tamu menginap di Hotel Green Eden dalam bulan Juni- Agustus 2017

\begin{tabular}{|c|c|c|c|c|}
\hline BULAN & $\begin{array}{c}\text { SUPERIOR } \\
(\mathbf{1})\end{array}$ & $\begin{array}{c}\text { DELUXE } \\
(\mathbf{2})\end{array}$ & $\begin{array}{c}\text { SUITE } \\
\mathbf{( 3 )}\end{array}$ & $\begin{array}{c}\text { JUMLAH } \\
(\mathbf{1})+(\mathbf{2})+(3)\end{array}$ \\
\hline Juni & 388 & 290 & 85 & 763 \\
\hline Juli & 302 & 225 & 89 & 616 \\
\hline Agustus & 281 & 211 & 65 & 557 \\
\hline
\end{tabular}

Sumber : Hotel Green Eden Manado

Jumlah hari tamu menginap hasilnya di dapatkan dari laporan pihak manajemen Hotel Green Eden Manado.

Tabel 4.3 Harga Pokok Kamar Hotel Green Eden

\begin{tabular}{|c|c|}
\hline Jenis Kamar & Harga Kamar (Rp) \\
\hline Superior & Rp. 400.000 \\
\hline Deluxe & Rp. 500.000 \\
\hline Suite & Rp. 650.000 \\
\hline
\end{tabular}

Sumber : Hotel Green Eden Manado

Perhitungan harga pokok kamar hotel Green Eden Manado oleh manajemen hotel dihitung berdasarkan jumlah biaya penggunaan tiap jenis kamar hotel selama bulan itu, dan dibagi dengan jumlah kamar hotel ditambah dengan biaya-biaya yang terkait langsung dengan aktivitas penginapan.

Tabel 4.4 Penentuan Cost Driver

\begin{tabular}{|l|l|l|l|}
\hline \multicolumn{1}{|c|}{ No } & \multicolumn{1}{|c|}{ Aktivitas } & \multicolumn{1}{c|}{ Level Aktivitas } & \multicolumn{1}{c|}{ Cost Driver } \\
\hline 1 & Aktivitas Penginapan & Unit Level & Jumlah Kamar Terjual \\
\hline 2 & Aktivitas Laundry & Unit Level & Jumlah Kamar Terjual \\
\hline 3 & Perlengkapan Kamar & Unit Level & Jumlah Kamar Terjual \\
\hline 4 & pemberian makan pagi & Unit Level & Jumlah Tamu Menginap \\
\hline 5 & Listrik dan air & Unit Level & Jumlah Kamar Terjual \\
\hline 6 & Aktivitas penyusutan & Facility Level & Luas lantai \\
\hline 7 & Administrasian & Unit Level & Jumlah Kamar Terjual \\
\hline 8 & Penggajian & Unit Level & Jumlah Jam Kerja \\
\hline 9 & Pemasaran & Product Level & Jumlah Kamar Tersedia \\
\hline 10 & Pemeliharaan dan & Facility Level & Luas lantai \\
\hline
\end{tabular}

Sumber : Data diolah 2018 
Dari tabel diatas dapat kita lihat bahwa terdapat beberapa aktivitas yang memiliki rasio konsumsi dan level aktivitas yang sama sehingga dapat dikelompokan dalam biaya yang sama.

1. Penentuan Tarif Kelompok per Unit

Setelah pengidentifikasian Cost Driver, langkah selanjutnya menentukan cost pool rate dengan cost driver. Tarif kelompok merupakan tarif biaya overhead per unit cost driver yang dihitung untuk sekelompok aktivitas. Hal ini dapat dihitung dengan rumus sebagai berikut:

\section{Jumlah Aktivitas \\ Tarif per unit Cost Driver =}

Cost Driver

Tabel 4.5 Tarif per unit Cost Driver (Bulan Juni)

\begin{tabular}{|l|l|c|c|}
\hline \multicolumn{1}{|c|}{ Cost Pool } & Tarif Cost Pool (1) & $\begin{array}{c}\text { Cost Driver } \\
(\mathbf{2})\end{array}$ & $\begin{array}{c}\text { Tarif/ Unit } \\
(\mathbf{1}):(\mathbf{2})\end{array}$ \\
\hline Cost Pool I & Rp. 43.065.315,-- & 763 & 56.442 \\
\hline Cost Pool II & Rp. 45.780.000,-- & 1.526 & 30.000 \\
\hline Cost Pool III & Rp. 12.852.117,- & 1.080 & 11.900 \\
\hline Cost Pool IV & Rp. 76.396.288,-- & 856 & 89.248 \\
\hline Cost Pool V & Rp. 106.856.291,-- & 4.608 & 23.189 \\
\hline
\end{tabular}

Sumber : data diolah 2018

Tabel 4.6 Tarif per unit Cost Driver (Bulan Juli)

\begin{tabular}{|l|l|c|c|}
\hline \multicolumn{1}{|c|}{ Cost Pool } & Tarif Cost Pool (1) & $\begin{array}{c}\text { Cost Driver } \\
\text { (2) }\end{array}$ & $\begin{array}{c}\text { Tarif/ Unit } \\
(\mathbf{1}):(\mathbf{2})\end{array}$ \\
\hline Cost Pool I & Rp. 37.216.226,-- & 616 & 60.415 \\
\hline Cost Pool II & Rp. 36.960.000,-- & 1.232 & 30.000 \\
\hline Cost Pool III & Rp. 12.646.767,- & 1.116 & 11.332 \\
\hline Cost Pool IV & Rp. 76.335.512,-- & 856 & 89.177 \\
\hline Cost Pool V & Rp. 100.947.874,-- & 4.608 & 21.907 \\
\hline
\end{tabular}

Sumber : data diolah 2018

Tabel 4.7 Tarif per unit Cost Driver (Bulan Agustus)

\begin{tabular}{|l|l|c|c|}
\hline \multicolumn{1}{|c|}{ Cost Pool } & Tarif Cost Pool (1) & $\begin{array}{c}\text { Cost Driver } \\
\text { (2) }\end{array}$ & $\begin{array}{c}\text { Tarif/ Unit } \\
(\mathbf{1}):(\mathbf{2})\end{array}$ \\
\hline Cost Pool I & Rp. 34.233.359,-- & 557 & 61,460 \\
\hline Cost Pool II & Rp. 33.420.000,-- & 1.114 & 30.000 \\
\hline Cost Pool III & Rp. 12.384.767,- & 1.116 & 11.097 \\
\hline Cost Pool IV & Rp. 75.772.264,- & 856 & 88.519 \\
\hline Cost Pool V & Rp. 101.228.484,-- & 4.608 & 21.967 \\
\hline
\end{tabular}

Sumber : data diolah 2018

2. Pembebanan biaya ke produk dan jasa menggunakan tarif Cost driver dan ukuran aktivitas

BOP dibebankan $=$ Tarif kelompok $\mathrm{X}$ unit Cost driver yang digunakan 
A. Bulan Juni

Tabel 4.8 Harga pokok kamar tipe Superior per hari (Bulan Juni)

\begin{tabular}{|l|c|r|r|}
\hline Cost Pool & Tarif Cost Pool & Cost driver & \multicolumn{1}{l|}{ Jumlah } \\
\hline Cost Pool I & Rp. 56.442 & 388 & 19.077 .396 \\
\hline Cost Pool II & Rp. 30.000 & 776 & 23.280 .000 \\
\hline Cost Pool III & Rp. 11.900 & 390 & 4.641 .000 \\
\hline Cost Pool IV & Rp. 81.385 & 448 & 36.460 .480 \\
\hline Cost Pool $\boldsymbol{V}$ & Rp. 23.189 & 2.304 & 53.427 .456 \\
\hline \multicolumn{2}{|l|}{ Total biaya tipe kamar Superior } & $\mathbf{1 3 6 . 8 8 6 . 3 3 2}$ \\
\hline Jumlah Kamar terjual & $\mathbf{3 5 2 . 7 9 9}$ \\
\hline \multicolumn{2}{|l|}{ Harga Pokok kamar Superior } \\
\hline
\end{tabular}

Sumber : Data diolah 2018

Tabel 4.9 Harga pokok kamar tipe Deluxe per hari (Bulan Juni)

\begin{tabular}{|l|c|r|r|}
\hline Cost Pool & Tarif Cost Pool & Cost driver & \multicolumn{1}{l|}{ Jumlah } \\
\hline Cost Pool I & Rp. 56.442 & 290 & 16.368 .180 \\
\hline Cost Pool II & Rp. 30.000 & 580 & 17.400 .000 \\
\hline Cost Pool III & Rp. 11.900 & 450 & 5.355 .000 \\
\hline Cost Pool IV & Rp. 81.385 & 484 & 39.390 .340 \\
\hline Cost Pool V & Rp. 23.189 & 1.905 & 44.175 .045 \\
\hline Total biaya tipe kamar Deluxe & & $\mathbf{1 2 2 . 6 8 8 . 5 6 5}$ \\
\hline Jumlah Kamar terjual & $\mathbf{2 9 0}$ \\
\hline Harga Pokok kamar Deluxe & $\mathbf{4 2 3 . 0 6 4}$ \\
\hline
\end{tabular}

Sumber : Data diolah 2018

Tabel 4.10 Harga pokok kamar tipe Suite per hari (Bulan Juni)

\begin{tabular}{|l|c|r|r|}
\hline Cost Pool & Tarif Cost Pool & Cost driver & \multicolumn{1}{l|}{ Jumlah } \\
\hline Cost Pool I & Rp. 56.442 & 85 & 4.797 .570 \\
\hline Cost Pool II & Rp. 30.000 & 170 & 5.100 .000 \\
\hline Cost Pool III & Rp. 11.900 & 240 & 2.856 .000 \\
\hline Cost Pool IV & Rp. 81.385 & 393 & 31.984 .305 \\
\hline Cost Pool V & Rp. 23.189 & 399 & 9.252 .411 \\
\hline \multicolumn{2}{|l|}{ Total biaya tipe kamar Suite } & & $\mathbf{5 3 . 9 9 0 . 2 8 6}$ \\
\hline Jumlah Kamar terjual & $\mathbf{8 5 5}$ \\
\hline Harga Pokok kamar Suite & $\mathbf{6 3 5 . 1 7 9}$ \\
\hline
\end{tabular}

Sumber : Data diolah 2018 
Tabel 4.11 Perbandingan Harga Pokok Kamar per Hari Menurut Hotel Green Eden Manado dan Menurut Activity Based Costing System

\begin{tabular}{|c|c|c|c|c|}
\hline Bulan & Jenis Kamar & $\begin{array}{c}\text { Harga Pokok } \\
\text { Kamar } \\
\text { Menurut Hotel } \\
\text { Green Eden } \\
\text { (Rp) }\end{array}$ & $\begin{array}{c}\text { Harga Pokok } \\
\text { Kamar } \\
\text { Menurut } \\
\text { Activity Based } \\
\text { Costing System } \\
\text { (Rp) }\end{array}$ & $\begin{array}{c}\text { Selisih } \\
\text { (Rp) }\end{array}$ \\
\hline \multirow{3}{*}{ Juni } & Superior & Rp. 400.000 & Rp. 352.799 & Rp. 47.201 \\
\cline { 2 - 5 } & Deluxe & Rp. 500.000 & Rp. 423.064 & Rp. 76.936 \\
\cline { 2 - 5 } & Suite & Rp. 650.000 & Rp. 635.179 & Rp. 14.821 \\
\hline \multirow{3}{*}{ Juli } & Superior & Rp. 400.000 & Rp. 449.475 & (- Rp. 49.475) \\
\cline { 2 - 6 } & Deluxe & Rp. 500.000 & Rp. 492.729 & Rp. 7.271 \\
\cline { 2 - 5 } Agustus & Suite & Rp. 650.000 & Rp. 613.557 & Rp. 36.443 \\
\cline { 2 - 6 } & Superior & Rp. 400.000 & Rp. 463,694 & ( - Rp. 63.694) \\
\cline { 2 - 5 } & Deluxe & Rp. 500.000 & Rp. 538.946 & (- Rp. 38.946) \\
\cline { 2 - 6 } & Suite & Rp. 650.000 & Rp. 873.456 & (- Rp. 223.456) \\
\hline
\end{tabular}

Sumber : Data diolah 2018

\subsection{Pembahasan}

Dalam penelitian ini saya mengambil 3 bulan data dari Hotel Green Eden, dengan tujuan untuk mencari tau informasi yang akurat proses penerapan Activity Based Costing System selain itu untu membandigkan harga pokok kamar yang dihitung oleh pihak manajemen hotel dan juga dengan menggunakan Activity Based Costing System. Dan juga saya ingin membandingkan hasil dari perhitungan Activity Based Costing System dari ketiga bulan tersebut apakah memiliki perbedaan harga pokok di masa Peak Season atau pun Low Season, karena hotel hanya berpatokan pada satu perkiraan harga pokok yang mereka gunakan. Oleh sebab itu saya mengambil data bulan Juni sampai Agustus.

Sesuai dengan perhitungan di atas, dapat diketahui bahwa hasil perhitungan harga pokok kamar dengan menggunakan Activity Based Costing System pada bulan Juni untuk jenis kamar Superior sebesar Rp. 352.799,- untuk kamar Deluxe sebesar Rp. 423.064,dan untuk kamar tipe Suite sebesar Rp.635.179,-. Kemudian untuk bulan Juli diketahui bahwa hasil perhitungan harga pokok kamar dengan menggunakan Activity Based Costing System untuk jenis kamar Superior sebesar Rp. 449.475,-, untuk kamar Deluxe sebesar Rp. 492.729,- dan untuk kamar tipe Suite sebesar Rp. 613.557,- $\quad$ Sedangkan untuk bulan Agustus diketahui bahwa hasil perhitungan harga pokok kamar dengan menggunakan Activity Based Costing System untuk jenis kamar Superior sebesar Rp. 463.694,- untuk kamar Deluxe sebesar Rp. 538.946,- dan untuk kamar tipe Suite sebesar Rp.873.456,-

\section{KESIMPULAN DAN SARAN}

\subsection{Kesimpulan}

Kesimpulan dari penelitian ini antara lain:

1. Hasilnya menunjukan perbendaan antara harga pokok kamar yang ditentukan oleh manajemen hotel dan penerapan Activity Based Costing System. Penggunaan metode Activity Based Costing dalam perhitungan harga pokok mengahasilkan harga pokok kamar yang lebih akurat itu dikarena biaya-biaya yang terjadi dibebankan pada produk atas dasar aktivitas dan menggunakan lebih dari satu Cost Driver.

2. Hasil dari perhitugan harga pokok kamar untuk bulan Juni, Juli, dan Agustus memiliki perbedaan hasil. 
- Dengan menggunakan Activity Based Costing untuk bulan Juni terlihat dari hasil yang ada untuk kamar Superior, Suite, dan Deluxe menghasilkan harga pokok kamar yang lebih rendah dibandingkan dengan perhitungan harga

\subsection{Saran} pokok kamar yang digunakan oleh pihak Manajemen Hotel.

1. Bagi pihak Hotel Green Eden Manado

Dari penelitian yang dilakukan dapat diketahui dengan menggunakan metode Activity Based Costing perusahaan dapat memperoleh informasi yang akurat tentang biaya karena metode ini merupakan system analisis biaya berbasis aktivitas. Saran saya agar pihak manajemen hotel bisa mempertimbangkan dan melakukan penelitian lebih lanjut mengenai penerapan Activity Based Costing dalam menghitung harga pokok, agar dapat memperoleh informasi yang tepat. Dan sebaiknya setiap bulannya harus dihitung kembali harga pokok untuk setiap jenis kamar hotel, agar tidak hanya berpatokan pada satu harga saja

2. Bagi peneliti selanjutnya agar dapat mencoba untuk mencari tau bagaimana perhitungan harga pokok kamar yang ditetapkan pihak hotel secara detail, karena saya memiliki keterbatasan penelitian dikarenakan pihak hotel tidak memberikan cara perhitungan mereka melainkan hanya hasil dari keseluruhannya saja.

\section{DAFTAR PUSTAKA}

Anggadini. 2012. Akuntansi Biaya. Yogyakarta. Graha Ilmu

Bustami, Bastian dan Nurlela. 2013. Akuntansi Biaya. Edisi 4. Jakarta; Mitrawakana media.

Dunia, dan Abdullah. 2012. Akuntansi Biaya. Edisi 3. Jakarta. Salemba Empat.

Garrison, Norren, dan Brewer. (2013). Akuntansi Manajerial. Jakarta: Salemba Empat.

Hansen, M.dan Mowen. 2012. Manajemen Biaya. Jakarta. Salemba Empat

Mulyadi. M. 2012. Akuntasi Biaya. Yogyakarta. Graha Ilmu

Nafarin, M. 2013. Penganggaran Perusahaan. Jakarta. Salemba Empat

Onat, dan Anitsal. 2014. Activity Based Costing in Service Industry; A Conceptial Framework for enterfeneurs. Vol. 19, 149 - 168

Panakenan. Indah. H.Sabijono. 2014. Penerapan Metode Activity Based Costing dalam Menentukan Tarif Jasa Rawat Inap pada Penginapan Villi Calaca Manado. Jurnal EMBA, Vol 2. No.2 Edisi Juni

Rudianto. R 2013. Akuntansi Manajemen Informasi untuk Pengambilan Keputusan Strategis. Jakarta. Erlangga

Siregar, dkk 2013. Akuntansi Manajemen. Jakarta. Salemba

Sugiyono. 2013. Metode Penelitian Kuantitatif, Kualitatif dan $R \& D$. Penerbit $\quad$ Alfabeta, Bandung 